\title{
An Immobilized Naphthylamide Substrate for Proteinases with Tryptic-Like Specificity
}

\author{
Deborah L. Higgins and Jules A. Shafer \\ Department of Biological Chemistry, The University of Michigan, \\ Ann Arbor, Michigan 48109
}

Received December 30, 1976; accepted July 29, 1977

\begin{abstract}
An immobilized amino acid naphthylamide substrate for proteinases with tryptic-like specificity was prepared by reacting $L$-arginine $\beta$-naphthylamide with an $N$-hydroxysuccinimide-activated derivative of agarose. Hydrolysis of the immobilized substrate (A10-Arg- $\beta \mathrm{NA}$ ) was followed by monitoring the increase in fluorescence accompanying the release of $\beta$-naphthylamine. Assays using A10-Arg- $\beta$ NA were designed for quantitatively determining the presence of 1-2 pmol of trypsin and $15 \mathrm{pmol}$ of thrombin. Profibrinolysin, fibrinolysin, and urokinase have either no or very low activities with A10-Arg- $\beta$ NA. Trypsin complexed with $\alpha_{2}$-macroglobulin has no activity $(<0.5 \%)$ toward A10-Arg- $\beta$ NA. The use of A10-Arg- $\beta$ NA for monitoring trypsin- $\alpha_{2}$-macroglobulin titrations was demonstrated.
\end{abstract}

Soluble naphthylamide derivatives of amino acids and peptides have been used widely as substrates in assays of proteolytic enzymes (e.g., $1-3)$, since the $\beta$-naphthylamine released on hydrolysis can be determined fluorometrically or colorimetrically, after a diazocoupling reaction. In this study, we describe the preparation and use of a naphthylamide substrate (A10-Arg- $\beta$ NA) linked to a solid support. Well-defined chromo-

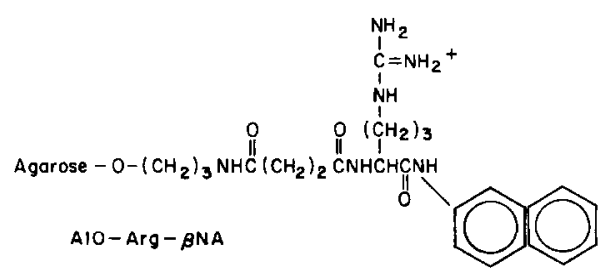

genic or fluorogenic substrates attached to a solid support should be useful in analyzing interactions of enzymes with other macromolecules. Whereas low molecular weight substrates may gain access to the active site of an enzyme on the interior of a supramolecular complex, substrates immobilized on a solid support would be expected to interact only with unblocked active sites on the surface of the complex. In addition to locating active sites in supramolecular complexes, substrates linked 
to solid supports should be useful in determining the importance of intermolecular interactions in the regulation of enzymes which have polymeric substrates.

\section{MATERIALS AND METHODS}

Preparation of A10-Arg- $\beta$ NA. L-Arginine $\beta$-naphthylamide $\mathrm{HCl}(150$ $\mu \mathrm{mol}$ from Vega-Fox Biochemicals) was added to $15 \mathrm{ml}$ of $0.1 \mathrm{M}$ phosphate buffer at $\mathrm{pH} 6.4$, and the mixture was stirred with a magnetic stirrer until most of the naphthylamide dissolved. The mixture then was added to $1 \mathrm{~g}$ of $N$-hydroxysuccinimide-activated agarose (Affigel 10 from Bio-Rad Laboratories). $N$-Hydroxysuccinimide-activated agarose also was prepared by succinylation of 3-aminopropyl agarose (Bio-Rad Laboratories) with succinic anhydride followed by activation with $N$ hydroxysuccinimide and $N, N^{\prime}$-dicyclohexylcarbodiimide $(4,5)$. The behavior and properties of $\mathrm{A} 10-\mathrm{Arg}-\beta \mathrm{NA}$ prepared from this activated agarose did not differ significantly from that prepared from the Affigel 10. Reaction of $N$-hydroxysuccinimide-activated agarose with L-arginine $\beta$-naphthylamide was allowed to proceed for $1.5 \mathrm{hr}$ at $4^{\circ} \mathrm{C}$ on a Burrell wrist-action shaker. The reaction mixture then was centrifuged, the supernatant solution was removed, and the resin was treated for $2 \mathrm{hr}$ at room temperature on the shaker with $15 \mathrm{ml}$ of $1.0 \mathrm{M}$ ethanolamine in $0.1 \mathrm{M}$ phosphate buffer at $\mathrm{pH}$ 6.5. After this treatment, the resin was washed on a Büchner funnel alternatively with 1 liter of $5 \mathrm{~mm}$ $\mathrm{HCl}$ and 1 liter of water until the washings yielded a negative response in a trinitrobenzenesulfonate test for amines (6). The resulting substrate (A10-Arg- $\beta$ NA) was washed in a $1-\mathrm{cm}$-diameter column at $4^{\circ} \mathrm{C}$ by elution for 2 days with 2 liters of distilled water, after which time the rate of release of fluorescent material from A10-Arg- $\beta$ NA corresponded to an apparent uncatalyzed rate of hydrolysis of less than $0.1 \% / \mathrm{hr}$ under the assay conditions (see below). The procedure described above was reproducible and yielded samples of immobilized substrate which behaved similarly in enzyme assays. Furthermore, the five preparations which were studied had similar concentrations of naphthylamide groups (3.8 $\pm 1 \mu \mathrm{mol} / \mathrm{ml}$ of settled resin). A10-Arg- $\beta$ NA was stored in the column at $4^{\circ} \mathrm{C}$ and eluted periodically with distilled water. The resin was stable for at least 3 months under these conditions.

Trypsin (bovine, TRL $2 \times$ recrystallized) was from Worthington Biochemical Corp. Urokinase, thrombin (human, A grade), and bovine serum albumin (A grade) were from Calbiochem. Fibrinolysin was obtained by activating $3 \mathrm{mg} / \mathrm{ml}$ of profibrinolysin from porcine blood (Sigma Chemical Co.) with 75 Plough units $/ \mathrm{ml}$ of urokinase in $0.04 \mathrm{M}$ Tris- $\mathrm{HCl}$ buffer, $\mathrm{pH} 8.1,0.01 \mathrm{M} \mathrm{CaCl}_{2}$. The fibrinolysin was used immediately after it reached maximal activity. $\alpha_{2}$-Macroglobulin (from human sera) was the generous gift of Dr. Margaret Hunter of this department. 
Assays with $\alpha, N$-tosyl-L-arginine methyl ester (Calbiochem) were performed according to the method of Hummel (7) and were used to check the catalytic activities of trypsin and fibrinolysin. Assays with $\alpha, N$ benzoyl-L-arginine ethyl ester (Aldrich Chemical Co.) were used to measure the activity of thrombin (8). The concentration of active trypsin was determined by titration of active sites with $p$-nitrophenyl guanidinobenzoate (Vega-Fox Biochemicals) according to the method of Chase and Shaw (9).

Assays with A10-Arg- $\beta$ NA were followed by monitoring the change in fluorescence associated with liberation of $\beta$-naphthalamine. Fluorescence measurements were made with an Aminco-Bowman spectrofluorometer (335-nm excitation, 410-nm emission). Assays were initiated by adding an aliquot of enzyme solution to a stirred suspension of A10Arg- $\beta \mathrm{NA}$ in $0.05 \mathrm{M}$ phosphate buffer, $\mathrm{pH} 7.4$, containing $0.1 \mathrm{mg} / \mathrm{ml}$ of bovine serum albumin. Assay tubes were kept in a constant-temperature $\left(25^{\circ} \mathrm{C}\right)$ bath, which consisted of a jacketed beaker through which water from a thermostated water circulator was pumped. Typical assays for trypsin employed $100 \mu \mathrm{l}$ of enzyme solution, $100 \mu \mathrm{l}$ of A10-Arg- $\beta$ NA, and $1 \mathrm{ml}$ of buffer. After an appropriate time interval (usually $60 \mathrm{~min}$ ), the assay tubes were centrifuged, whereupon a $0.1-\mathrm{ml}$ aliquot of the supernatant solution was immediately diluted into $1.0 \mathrm{ml}$ of $0.05 \mathrm{M}$ phosphate buffer, $\mathrm{pH} 7.4$, and its fluorescence was determined. Rates of substrate hydrolysis were calculated using the time elapsed between addition of enzyme and centrifugation. After the assay, trypsin, $2 \mathrm{mg}$ in $0.1 \mathrm{ml}$ of $1 \mathrm{~mm} \mathrm{HCl}$, was added to the resin suspension. The resin suspension was stirred for $1 \mathrm{hr}$ and centrifuged. The fluorescence of the resulting supernatant solution was determined in order to determine the exact amount of substrate initially present. Concentrations of $\beta$-naphthylamine were determined from the measured fluorescence, and the linear relationship established between the concentration and fluorescence of $\beta$-naphthylamine (Sigma Chemical Co.) in $0.05 \mathrm{M}$ phosphate buffer, $\mathrm{pH}$ 7.4. Rates were corrected for the uncatalyzed hydrolysis of the resin by subtracting the fraction of substrate hydrolyzed in a noenzyme blank from the observed fraction of substrate hydrolyzed in the sample.

Assays with a soluble naphthylamide, substrate, $\alpha, N$-benzyloxycarbonyl-L-arginine $\beta$-naphthylamide (Vega-Fox Biochemicals), were identical to those described using A10-Arg- $\beta$ NA except that the assay mixture contained $68 \mu \mathrm{M} \alpha, N$-benzyloxycarbonyl-L-arginine $\beta$-naphthylamide instead of A10-Arg- $\beta$ NA.

\section{RESULTS AND DISCUSSION}

Figure 1 shows the dependence on time of the trypsin-catalyzed release of $\beta$-naphthylamine from $L$-arginine $\beta$-naphthylamide covalently 


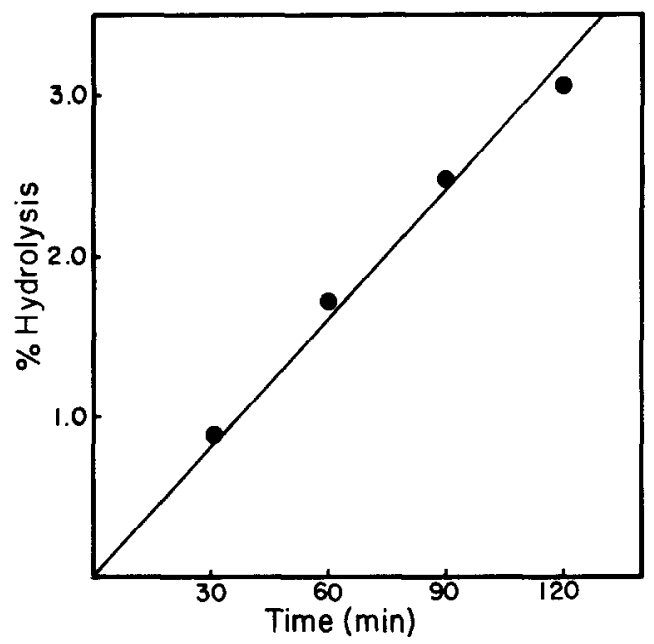

FIG. 1. Time dependence of trypsin-catalyzed release of $\beta$-naphthylamine from A10Arg- $\beta$ NA $(400 \mu \mathrm{l}$ of resin, $4.39 \mathrm{ml}$ of $0.05 \mathrm{M}$ phosphate buffer, $\mathrm{pH} 7.4$, containing 0.1 $\mathrm{mg} / \mathrm{ml}$ of bovine serum albumin, and $21 \mathrm{pmol}$ of trypsin in $10 \mu \mathrm{l}$ of $0.001 \mathrm{~N} \mathrm{HCl}$ ). At the indicated times, the reaction mixture was centrifuged, and a $0.1-\mathrm{ml}$ aliquot was withdrawn to measure the amount of $\beta$-naphthylamine released. After the final time point, excess trypsin was added to obtain the amount of substrate initially present.

linked to Affigel 10 (A10-Arg- $\beta$ NA). Initial rates of hydrolysis of A10Arg- $\beta$ NA were obtained from the linear time dependence of $\beta$-naphthylamine released from the substrate (Fig. 1). Substrate hydrolysis was monitored to degrees of conversion of less than $3 \%$ in order to ensure that the determination of initial velocities was not complicated by deviations from linearity due to the depletion of substrate $\left(S_{0}\right.$ in Eq. [1], see below) or the possible presence of sites of varying activity. It should be noted, however, that the choice of $3 \%$ was arbitrary, and no systematic deviations from linearity could be detected below about $6 \%$ conversion.

In the concentration range studied, the initial rate of release of $\beta$ naphthylamine from the substrate was first order with respect to the amount of substrate in the assay mixture (Fig. 2). Because of the difficulty in reproducibly pipetting the resin suspension, the amount of substrate in each assay solution was determined. After determining the amount of substrate $(\Delta S)$ hydrolyzed during the assay, the assay mixture was incubated with excess trypsin. The amount of $\beta$-naphthylamine present after this incubation yielded the amount of substrate $\left(S_{0}\right)$ initially present.

In the concentration range of substrate where an enzymically catalyzed reaction is first order with respect to the concentration of substrate, the fraction of substrate hydrolyzed per unit time $\left(v_{f}\right)$ above a no-enzyme blank is proportional to the enzyme concentration $(e)$ as indicated by Eq. [1], 


$$
v_{\mathrm{f}}=\frac{d\left(\Delta S / S_{0}\right)}{d t}=k e,
$$

where $k$ is the ratio of the turnover number to the Michaelis constant for the enzyme with the immobilized substrate. A value of $1200 \mathrm{sec}^{-1} \mathrm{M}^{-1}$ for $k$ was obtained for the trypsin-catalyzed hydrolysis of A10-Arg- $\beta \mathrm{NA}$ at $25^{\circ} \mathrm{C}, \mathrm{pH}$ 7.4. Valucs of $v_{\mathrm{f}}$ for enzymically catalyzed hydrolysis of immobilized substrate were evaluated using Eq. [2],

$$
v_{\mathrm{f}}=\left[F_{t} / F_{\mathrm{f}} t\right]_{\text {sample }}-\left[F_{t} / F_{\mathrm{f}} t\right]_{\text {hlank }},
$$

where $F_{t}$ and $F_{\mathrm{f}}$ represent fluorescence readings after assay time $t$ and after addition of excess trypsin, respectively. The expected first-order dependence of $v_{\mathrm{f}}$ on the concentration of trypsin (Fig. 3) indicates that this immobilized naphthylamide can be used as a substrate in assays for tryptic activity. The assay described here easily can be used to determine quantitatively the presence of 1-2 pmol of trypsin, since the no-enzyme blanks are more than doubled by about $0.3 \mathrm{pmol}$ of trypsin. The rate of

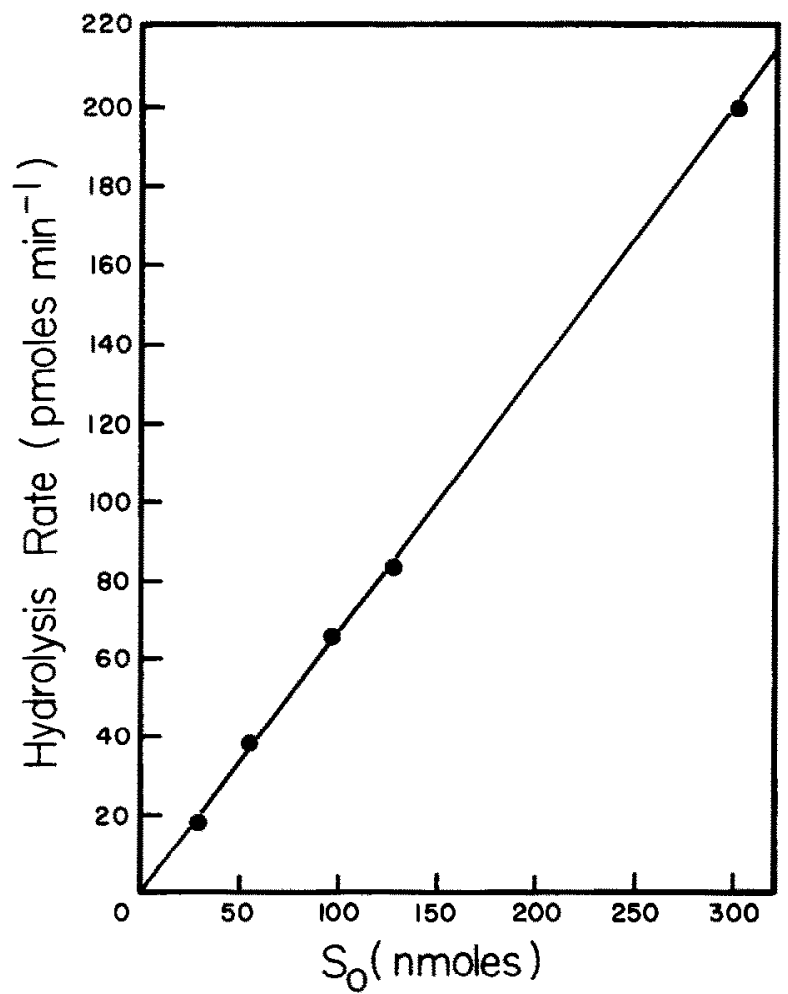

FIG. 2. Dependence of the rate of the trypsin-catalyzed release of $\beta$-naphthylamine on the amount of substrate initially present $(14.4 \mathrm{pmol}$ of trypsin, total volume $1.30 \mathrm{ml}$, pH 7.4). 


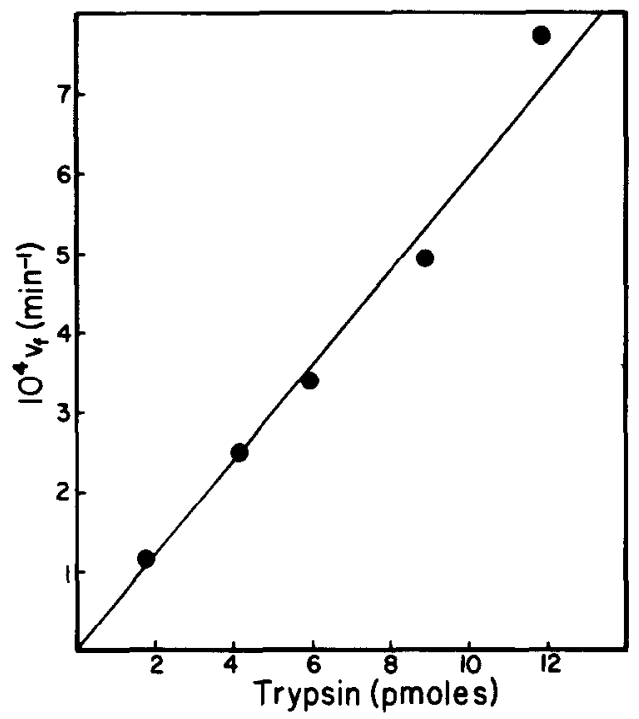

FIG. 3. Dependence of the initial rate of trypsin-catalyzed release of $\beta$-naphthylamine on the amount of trypsin in the assay $(100 \mu \mathrm{l}$ of $\mathrm{A} 10-\mathrm{Arg}-\beta \mathrm{NA}$, total volume 1.20 $\mathrm{ml}, \mathrm{pH}$ 7.4).

the trypsin-catalyzed hydrolysis of A10-Arg- $\beta \mathrm{NA}$ was compared to that of a soluble naphthylamide substrate, $\alpha, N$-benzyloxycarbonyl-L-arginine $\beta$-naphthylamide. With the substrates at $68 \mu \mathrm{M}$, the rate of the trypsincatalyzed hydrolysis was three times greater for the soluble substrate than for A10-Arg- $\beta$ NA. Thus in assays for detecting the presence of trypsin, the immobilized substrate appears to give a sensitivity comparable to soluble naphthylamide substrates.

The activities of other proteinases toward A10-Arg- $\beta$ NA also were tested. A10-Arg- $\beta$ NA was a good substrate for thrombin. The presence of less than $15 \mathrm{pmol}$ of thrombin could be determined quantitatively using an assay analogous to that described for trypsin. No urokinase (16.6 Plough units $/ \mathrm{ml})$ - or profibrinolysin $(1 \mathrm{mg} / \mathrm{ml})$-catalyzed hydrolysis was detected in assays which contained $340 \mathrm{nmol} / \mathrm{ml}$ of A10-Arg- $\beta \mathrm{NA}$. Fibrinolysin-catalyzed hydrolysis could be detected, however, at concentrations greater than $0.28 \mathrm{mg} / \mathrm{ml}$ in assays which contained $340 \mathrm{nmol} / \mathrm{ml}$ of A10-Arg- $\beta$ NA.

The use of A10-Arg- $\beta$ NA for monitoring formation of a trypsin $-\alpha_{2}$ macroglobulin complex was investigated. Trypsin when complexed with $\alpha_{2}$ macroglobulin has been reported to retain $50 \%$ or more of its activity toward low molecular weight substrates, whereas the complexed enzyme has little or no activity toward high molecular weight substrates (10). We found that trypsin complexed with $\alpha_{2}$-macroglobulin retains $50 \%$ of its activity toward the soluble naphthylamide substrate $\alpha$-N-benzyloxycarbonyl-L-arginine $\beta$-naphthylamide. Trypsin complexed with $\alpha_{2}$ - 


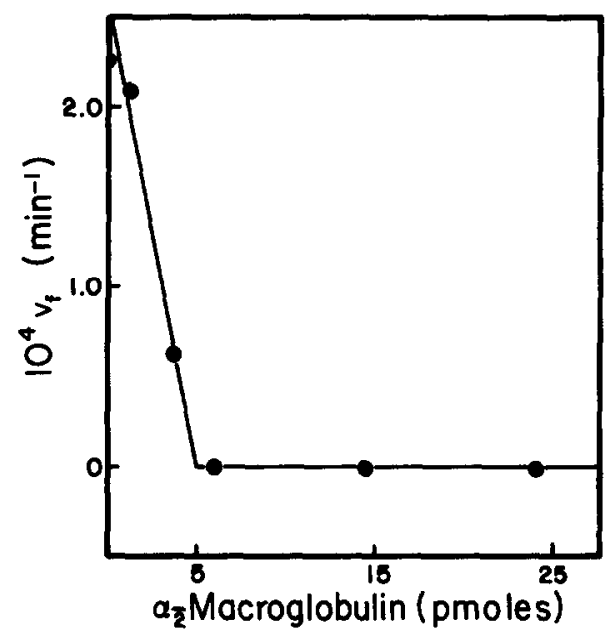

FIG. 4. Dependence of the initial rate of trypsin-catalyzed release of $\beta$-naphthylamine on the amount of $\alpha_{2}$-macroglobulin present (100 $\mu$ l of A10-Arg- $\beta \mathrm{NA}, 4.3 \mathrm{pmol}$ of trypsin, total volume $1.20 \mathrm{ml}, \mathrm{pH} 7.4$ ).

macroglobulin, however, appears to have little or no activity toward A10Arg- $\beta$ NA. In an attempt to measure the catalytic activity of complexed trypsin toward the immobilized naphthylamide substrate, high concentrations of trypsin in the presence of excess $\alpha_{2}$-macroglobulin were assayed with A10-Arg- $\beta$ NA. The observation that assays of $213 \mathrm{pmol}$ of trypsin in the presence of excess $\alpha_{2}$-macroglobulin ( $420 \mathrm{pmol}$, see below) yield rates of hydrolysis of A10-Arg- $\beta$ NA below that given by 1 pmol of free trypsin indicates that trypsin in the $\alpha_{2}$-macroglobulin complex retains less than $0.5 \%$ of its native activity toward A10-Arg- $\beta$ NA. Figure 4 shows the activity of 4.3 pmol of active trypsin toward the immobilized substrate as a function of the $\alpha_{2}$-macroglobulin concentration. The titration depicted in Fig. 4 indicates a 1:1 stoichiometry for the trypsin- $\alpha_{2}$-macroglobulin complex in agreement with that reported by Barrett and Starkey (10).

Thus, A10-Arg- $\beta$ NA should be useful in quantitative determinations of interactions of proteolytic enzymes with $\alpha_{2}$-macroglobulin and other supramolecular structures, for example, cell surfaces.

\section{ACKNOWLEDGMENTS}

Financial support of this work by NIH Research Grant AI12625 and Training Grant GM00187 is gratefully acknowledged.

\section{REFERENCES}

1. McDonald, J. K., Ellis, S., and Reilly, T. J. (1966) J. Biol. Chem. 241, 1494-1501.

2. Barrett, A. J. (1976) Anal. Biochem. 76, 374-376.

3. Nachlas, M. M., Plapinger, R. E., and Seligman, A. M. (1964) Arch. Biochem. Biophys. 108, 266-274. 
4. Cuatrecasas, P. (1970) J. Biol. Chem. 245, 3059-3065.

5. Cuatrecasas, P., and Parikh, I. (1972) Biochemistry 11, 2291-2299.

6. Inman, J. K., and Dintzis, H. M. (1969) Biochemistry 8, 4074-4082.

7. Hummel, B. C. W. (1959) Canad. J. Biochem. Physiol. 37, 1393-1400.

8. Kezdy, F. J., Lorand, L., and Miller, K. D. (1965) Biochemistry 4, 2302-2308.

9. Chase, T., Jr., and Shaw, E. (1970) in Methods in Enzymology (Perlmann, G. E., and Lorand, L., eds.), Vol. 19, pp. 20-27, Academic Press, New York.

10. Barrett, A. J., and Starkey, P. M. (1973) Biochem. J. 133, 709-724 (and work cited therein). 